\title{
pH-responsive disruption of 'liquid marbles' prepared from water and poly(6-(acrylamido) hexanoic acid)-grafted silica particles
}

\begin{abstract}
Masamichi Inoue ${ }^{1}$, Syuji Fujii ${ }^{2}$, Yoshinobu Nakamura ${ }^{2}$, Yasuhiko Iwasaki ${ }^{3}$ and Shin-ichi Yusa ${ }^{1}$
A chain transfer agent was immobilized onto the surface of $11-\mu \mathrm{m}$ diameter silica particles $\left(\mathrm{CPD}-\mathrm{SiO}_{2}\right)$ for use in reversible addition-fragmentation chain transfer (RAFT)-controlled radical polymerization. pH-responsive poly(6-(acrylamido)hexanoic acid) $(\mathrm{PAaH})$-grafted silica particles $\left(\mathrm{PAaH}-\mathrm{SiO}_{2}\right)$ were prepared via RAFT-controlled radical polymerization using $\mathrm{CPD}-\mathrm{SiO}_{2}$. Immobilization of the PAaH chains onto the surface of silica particles was confirmed by thermogravimetric analysis, attenuated total reflection-Fourier transfer infrared and scanning electron microscopy measurements. The solubility of PAaH in water is strongly dependent on the $\mathrm{pH}$ of the solution. $\mathrm{PAaH}-\mathrm{SiO}_{2}$ was flocculated at $\mathrm{pH} 3$ because of the hydrophobic interaction of the grafted $\mathrm{PAaH}$ chains with protonated carboxyl pendant groups. In contrast, $\mathrm{PAaH}-\mathrm{SiO}_{2}$ was dispersed at $\mathrm{pH} 10$ because of electrostatic repulsion between the grafted PAaH chains with pendant carboxylate ions. Millimeter-sized 'liquid marbles' can be prepared using the $\mathrm{pH}$-responsive $\mathrm{PAaH}_{-} \mathrm{SiO}_{2}$ particles. The 'liquid marble' can be transferred intact onto the surface of a neutral or acidic water pool and exhibit long-term stability. When the pH of the water pool becomes alkaline, the 'liquid marble' immediately bursts on the surface of the water pool.
\end{abstract}

Polymer Journal (2011) 43, 778-784; doi:10.1038/pj.2011.55; published online 22 June 2011

Keywords: controlled radical polymerization; graft; liquid marble; pH-responsive polymer

\section{INTRODUCTION}

There has been increased interest in solid particles adsorbed to liquidliquid, gas-liquid and gas-solid interfaces. An emulsion can be stabilized by solid particles adsorbed to an oil-water (liquid-liquid) interface, which is known as a Pickering emulsion. ${ }^{1-3}$ Such emulsions have been extensively studied over the last decade. ${ }^{4,5}$ Furthermore, 'liquid marbles', which are stabilized by solid particles adsorbed at gasliquid interfaces, have attracted increasing attention with respect to their potential applications in cosmetics, pharmaceuticals and in home and personal care products. ${ }^{6-9}$ 'Liquid marbles' are liquid-in-gas dispersed systems prepared using relatively hydrophobic particles adsorbed onto a gas-liquid interface. It has been reported that inorganic particles such as silica, ${ }^{10-13}$ graphite, ${ }^{14}$ synthetic polymer particles ${ }^{15-18}$ and surface-modified lycopodium powder ${ }^{19}$ can be used as effective 'liquid marble' stabilizers. The 'liquid marbles' that are coated with hydrophobic particles can float on the water surface and remain intact on glass. One of the present authors has reported the preparation of $\mathrm{pH}$-responsive 'liquid marbles. ${ }^{.20,21}$ In this case, particles with $\mathrm{pH}$-responsive cationic polymers, such as poly(2-(diethylamino)ethyl methacrylate) or poly(2-vinylpyridine), on their surfaces were used as 'liquid marble' stabilizers. 'Liquid marbles' on the surface of the water pool immediately disintegrated upon addition of acid to the pool, because the weakly alkaline nature of the particle surface confers $\mathrm{pH}$-responsive behavior. In order to widen the application range of liquid marbles, it is important to develop $\mathrm{pH}$-responsive liquid marbles stabilized with anionic polymer-modified particles, which can be disrupted on addition of alkaline solution. However, there has been no study on alkaline-induced breakable liquid marbles as far as we are aware. Herein, we have investigated the stability control of 'liquid marbles' prepared using poly(6-(acrylamido)hexanoic acid) $(\mathrm{PAaH})$-grafted micrometer-sized silica particles $\left(\mathrm{PAaH}-\mathrm{SiO}_{2}\right)$ used as 'liquid marble' stabilizers, by tuning their surface hydrophobicity/ hydrophilicity with external $\mathrm{pH}$ stimuli. Under acidic and neutral $\mathrm{pH}$ conditions, the surface of $\mathrm{PAaH}-\mathrm{SiO}_{2}$ is hydrophobic, because the pendant carboxyl groups in $\mathrm{PAaH}$ are protonated. However, under alkaline conditions, $\mathrm{PAaH}$ can dissolve in water and the wettability of the surface of $\mathrm{PAaH}-\mathrm{SiO}_{2}$ increases, because the pendant carboxyl groups are deprotonated to form carboxylate ions. It is expected that $\mathrm{PAaH}-\mathrm{SiO}_{2}$ can stabilize 'liquid marbles' on the surface of an acidic or neutral water pool; however, the 'liquid marbles' would disintegrate upon the addition of an alkali.

Grafting a polymer to a solid surface involves polymer chains grafted to the solid substrate (grafting to), or the grafting reaction can proceed by polymerization from the surface (grafting from).

${ }^{1}$ Department of Materials Science and Chemistry, University of Hyogo, Himeji, Japan; ${ }^{2}$ Department of Applied Chemistry, Osaka Institute of Technology, Osaka, Japan and ${ }^{3}$ Faculty of Chemistry, Materials and Bioengineering, Kansai University, Osaka, Japan 

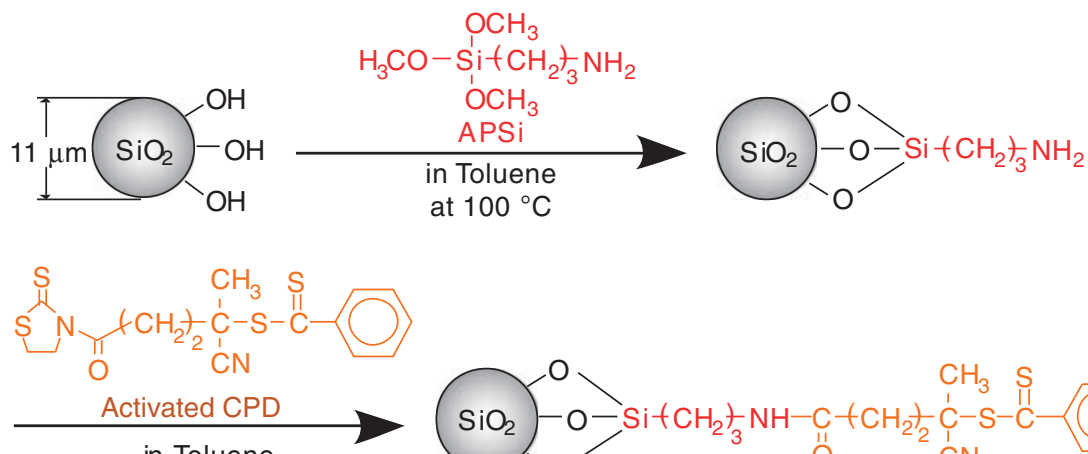

in Toluene

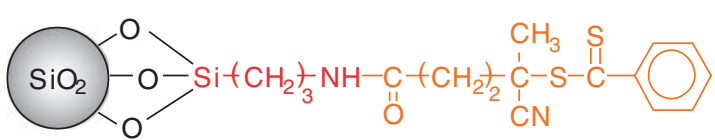

at roomtemperature

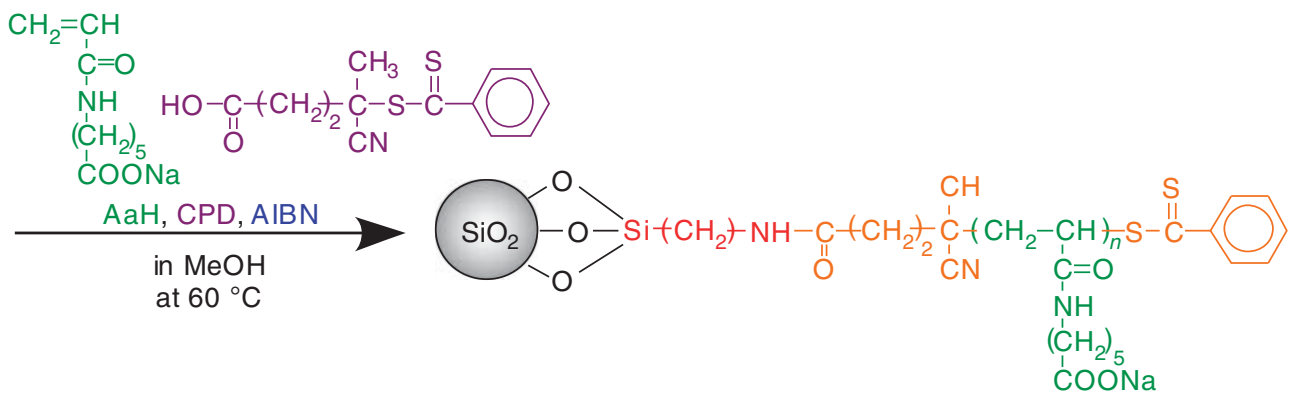

Scheme 1 Synthetic route for $\mathrm{pH}$-responsive PAaH-grafted silica particles $\left(\mathrm{PAaH}-\mathrm{SiO}_{2}\right)$ via RAFT-controlled radical polymerization.

In both cases a thin polymer layer can be formed on the solid surface. However, it is difficult to form a polymer layer with high density using the grafting to approach. Therefore, we performed the grafting from the method to graft PAaH onto the surface of silica particles in order to prepare a high-density polymer layer. Many researchers have studied the controlled radical polymerization at the surface of a solid particle; for example, Lattuada et al..$^{22}$ reported that poly(acrylic acid) was grafted to magnetic nanoparticles via atom transfer radical polymerization. Zhao et al. ${ }^{23}$ reported that vinyl monomers such as methyl acrylate, $n$-butyl acrylate, $N, N$-dimethylacrylamide, $N$-isopropylacrylamide, methyl methacrylate and styrene could be grafted to silica via reversible RAFT-controlled radical polymerization.

In this work, $\mathrm{PAaH}-\mathrm{SiO}_{2}$ was prepared via the grafting from approach with a RAFT-controlled radical polymerization method (Scheme 1). The stability of $\mathrm{pH}$-responsive 'liquid marbles' formed on a water surface using $\mathrm{PAaH}-\mathrm{SiO}_{2}$ was studied at various $\mathrm{pH}$. These $\mathrm{PAaH}-\mathrm{SiO}_{2}$ particles are shown to be interesting novel $\mathrm{pH}$-responsive particulate 'liquid marble' stabilizers. This study shows the first example of $\mathrm{pH}$-responsive 'liquid marbles' that can disintegrate upon addition of alkali, rather than acid.

\section{EXPERIMENTAL PROCEDURE}

\section{Materials}

Silica particles $\left(\mathrm{SiO}_{2}\right)$ with diameters of $11 \mu \mathrm{m}$ (HIPRESICA, Ube-Nitto Kasei, Tokyo, Japan) were used after drying under reduced pressure at $100{ }^{\circ} \mathrm{C}$ for 3 days. 2,2'-azobis(isobutyronitrile) (98\%, Wako Pure Chemical Industries, Osaka, Japan) was used after recrystallization from methanol. 4-Cyanopentanoic acid dithiobenzoate (CPD $)^{24}$ and sodium 6-(acrylamido)hexanoate $(\mathrm{AaH})^{25}$ were synthesized according to previously reported methods. Toluene, methanol and dichloromethane were dried over $4 \AA$ molecular sieves and purified by distillation. 3-Aminopropyltriethoxysilane (APSi; 96\%, Tokyo Chemical Industry, Tokyo, Japan), 1,3-dicyclohexylcarbodiimide (95\%, Kishida Chemical, Osaka, Japan), 4-(dimethylamino)pyridine (99\%, Toyo Gosei, Tokyo, Japan), 2-mercapto-2-thiazoline (88\%, Wako Pure Chemical Industries), safranin (80\%, Kanto Chemical, Tokyo, Japan) and gelatin from bovine bone
(Wako Pure Chemical Industries) were used as received. Water was purified using a Millipore Milli-Q system (Millipore, Billerica, MA, USA). Other reagents were used as received.

Synthesis of amino group-immobilized silica particles $\left(\mathrm{APSi}^{-\mathrm{SiO}_{2}}\right)$ $\mathrm{SiO}_{2}$ particles $(10.0 \mathrm{~g})$ were dispersed in dry toluene $(330 \mathrm{ml})$ using ultrasonication for $20 \mathrm{~min}$, after which APSi $(10.0 \mathrm{~g}, 55.9 \mathrm{mmol})$ was added to the solution. The solution was heated at $100^{\circ} \mathrm{C}$ for $18 \mathrm{~h}$ with stirring. After the reaction, the silica particles were washed by centrifugation at 6000 r.p.m. for $30 \mathrm{~min}$ in acetone (three times) and then dried in a vacuum oven at $100^{\circ} \mathrm{C}$ overnight to obtain APSi-immobilized silica particles $\left(\mathrm{APSi}-\mathrm{SiO}_{2}, 7.55 \mathrm{~g}\right)$.

\section{Synthesis of activated CPD}

CPD (10.0 g, $35.8 \mathrm{mmol}), 2$-mercapto-2-thiazoline $(4.27 \mathrm{~g}, 35.8 \mathrm{mmol})$ and 4-(dimethylamino)pyridine $(0.438 \mathrm{~g}, \quad 3.59 \mathrm{mmol})$ were dissolved in distilled dichloromethane $(120 \mathrm{ml}){ }^{26,27} 1,3$-Dicyclohexylcarbodiimide (9.65 g, $46.8 \mathrm{mmol})$ in distilled dichloromethane $(80 \mathrm{ml})$ was added dropwise to the solution under an Ar atmosphere and the reaction mixture was then stirred at room temperature for $18 \mathrm{~h}$. The solvent was removed by evaporation and purified by silica column chromatography using chloroform as an eluent. Activated CPD was obtained as a red oil $(3.61 \mathrm{~g}, 24.4 \%) .{ }^{1} \mathrm{H} \mathrm{NMR}(500 \mathrm{MHz}$, $\left.\mathrm{CDCl}_{3}\right): \delta$ (p.p.m.) $1.94(\mathrm{~s}, 3 \mathrm{H}), 2.56-3.01(\mathrm{~m}, 4 \mathrm{H}), 3.13(\mathrm{t}, 1 \mathrm{H}), 4.58(\mathrm{t}, 1 \mathrm{H})$, $7.40(\mathrm{~m}, 2 \mathrm{H}), 7.56(\mathrm{~m}, 1 \mathrm{H}), 7.90(\mathrm{~m}, 2 \mathrm{H})$.

\section{Synthesis of CPD-immobilized silica particles $\left(\mathrm{CPD}-\mathrm{SiO}_{2}\right)$}

$\mathrm{APSi}_{-} \mathrm{SiO}_{2}(3.60 \mathrm{~g})$ and activated CPD $(3.61 \mathrm{~g}, 9.50 \mathrm{mmol})$ were dispersed in dry toluene $(132 \mathrm{ml})$ and the reaction was carried out at room temperature for $20 \mathrm{~h}$ with stirring. After the reaction, the particles were washed by centrifugation at 6000 r.p.m. for $30 \mathrm{~min}$ in acetone (3 times) and then dried in a vacuum oven at $120^{\circ} \mathrm{C}$ overnight to obtain $\mathrm{CPD}$-immobilized silica particles $\left(\mathrm{CPD}-\mathrm{SiO}_{2}, 3.33 \mathrm{~g}\right)$.

\section{Synthesis of PAaH-grafted silica particles $\left(\mathrm{PAaH}-\mathrm{SiO}_{2}\right)$}

CPD $-\mathrm{SiO}_{2}(1.20 \mathrm{~g}), \mathrm{CPD}(5.1 \mathrm{mg}, 0.0183 \mathrm{mmol}), \mathrm{AaH}(1.00 \mathrm{~g}, 5.41 \mathrm{mmol})$ and $2,2^{\prime}$-azobis(isobutyronitrile) $(1.4 \mathrm{mg}, 0.00853 \mathrm{mmol})$ were dispersed in methanol $(8.63 \mathrm{ml})$. The polymerization was performed at $60^{\circ} \mathrm{C}$ for $24 \mathrm{~h}$ with 
stirring under an Ar atmosphere. After polymerization, the supernatant was measured by gel-permeation chromatography, and the particles were dispersed in a $\mathrm{pH} 3$ aqueous solution and then precipitated by centrifugation at 6000 r.p.m. for $30 \mathrm{~min}$. The precipitated particles were washed by centrifugation at 6000 r.p.m. for $30 \mathrm{~min}$ in methanol (two times) and in acetone (three times). The particles were dried in a vacuum oven at $120^{\circ} \mathrm{C}$ overnight to yield $\mathrm{PAaH}-$ grafted silica particles $\left(\mathrm{PAaH}-\mathrm{SiO}_{2}, 1.00 \mathrm{~g}\right)$.

\section{Preparation of 'liquid marbles'}

Pure water or safranin dye-containing water was dispensed as $7 \mu \mathrm{l}$ droplets and mixed with the dried $\mathrm{PAaH}-\mathrm{SiO}_{2}$ particles. Under these conditions, the $\mathrm{PAaH}$ $\mathrm{SiO}_{2}$ powder spontaneously coats the water droplet, which then behaves as a perfectly non-wetting 'liquid marble' when transferred either onto a glass slide or onto the surface of a water pool. ${ }^{28}$

\section{Measurements}

${ }^{1} \mathrm{H}$ NMR. ${ }^{1} \mathrm{H}$ NMR spectra were obtained with a Bruker BioSpin (Billerica, MA, USA) DRX 500 FT-NMR spectrometer.

Gel-permeation chromatography. Gel-permeation chromatography was performed using a refractive index detector equipped with a Shodex $7.0 \mu \mathrm{m}$ bead size GF-7M HQ column (exclusion limit $\sim 10^{7}$, Showa Denko K. K., Tokyo, Japan) operated at $40{ }^{\circ} \mathrm{C}$ under a flow rate of $0.6 \mathrm{ml} \mathrm{min}^{-1}$. A phosphate buffer ( $\mathrm{pH} 9$, $50 \mathrm{~mm}$ ) containing $10 \mathrm{vol} \%$ acetonitrile was used as an eluent. The values of $M_{\mathrm{n}}$ and $M_{\mathrm{w}} / M_{\mathrm{n}}$ were calibrated according to standard sodium poly(styrenesulfonate) samples of different molecular weights ranging from $1.37 \times 10^{3}$ to $2.16 \times 10^{6}$.

Attenuated total reflection-Fourier transform infrared. Attenuated total reflection-Fourier transfer infrared spectra were recorded using a Jasco (Tokyo, Japan) FT/IR-4200 spectrophotometer with an ATR PRO450-S base kit and ZnSe prism. Spectra were collected over 64 scans with a spectral resolution of $1.0 \mathrm{~cm}^{-1}$.

Thermogravimetric analysis. Thermogravimetric analysis was performed using an Exstar TG/DTA 6200 apparatus (SII Nano Technology, Chiba, Japan) under nitrogen with a flow rate of $100 \mathrm{ml} \mathrm{min}^{-1}$ and a heating rate of $2{ }^{\circ} \mathrm{C}$ per min. The graft density of the polymer $(\Gamma)$, the distance between graft sites $(D)$ and the thickness of the grafted polymer layer $(H)$ were estimated according to the following Equations:

$$
\begin{aligned}
& \Gamma=\frac{R \rho_{\mathrm{SiO}_{2}} \phi_{\text {polymer }} N_{\mathrm{A}}}{3 M_{\mathrm{n}}\left(1-\phi_{\text {polymer }}\right)} \\
& D=\Gamma^{-0.5} \\
& H=\frac{\Gamma M_{\mathrm{n}}}{\rho_{\text {polymer }} N_{\mathrm{A}}}
\end{aligned}
$$

where $R$ is the radius of the silica particle $(=5.5 \mu \mathrm{m}), \rho_{\mathrm{SiO} 2}$ and $\rho_{\text {polymer }}$ are the mass density of the silica particles $\left(1.93 \mathrm{~g} \mathrm{~cm}^{-3}\right)$ and polymer, respectively, $\phi_{\text {polymer }}$ is the mass fraction of the polymer (obtained from TGA) and $N_{\mathrm{A}}$ is the Avogadro number. ${ }^{29,30}$

Scanning electron microscopy. Scanning electron microscopy (SEM) images were obtained using a VE-9800 (Keyence, Osaka, Japan) for all silica particle samples operating at $5 \mathrm{kV}$. SEM samples were coated with platinum using a Sanyu Electron Quick Coater SC-701 Mk-II (Sanyu Electron, Tokyo, Japan).

Percent transmittance (\%T). The $\% T$ was measured at $600 \mathrm{~nm}$ using a Jasco V-530 UV-Vis spectrophotometer with quartz cells having a path length of $1.0 \mathrm{~cm}$. Measurements were recorded at predetermined time intervals for dispersed $\mathrm{PAaH}-\mathrm{SiO}_{2}$ with a concentration of $4.0 \mathrm{gl}^{-1}$ in water adjusted to $\mathrm{pH} 3$ and 10 with aqueous $\mathrm{HCl}$ and $\mathrm{NaOH}$ solutions.

Optical microscopy. Optical microscopy images were obtained using a Keyence VHX-100 microscope with a VHZ-450 zoom lens. The pH of $\mathrm{PAaH}_{-} \mathrm{SiO}_{2}$ dispersions in water were adjusted to 3 and 10 using aqueous $\mathrm{HCl}$ and $\mathrm{NaOH}$ solutions. The water dispersion of the $\mathrm{PAaH}-\mathrm{SiO}_{2}$ particles was placed between a glass slide and a cover glass for microscopic observation. A Keyence (Osaka, Japan) VH-Z00R zoom lens was used to record photographic images of the millimeter-sized 'liquid marbles.'

\section{RESULTS AND DISCUSSION}

$\mathrm{CPD}-\mathrm{SiO}_{2}$ particles can be used for the RAFT-controlled radical polymerization of $\mathrm{AaH}$ in methanol (Scheme 1). We have performed the polymerization of $\mathrm{AaH}$ in the presence of $\mathrm{CPD}-\mathrm{SiO}_{2}$ and $\mathrm{CPD}$ as a free chain transfer agent. ${ }^{31}$ After the polymerization, $\mathrm{PAaH}-\mathrm{SiO}_{2}$ was isolated from free $\mathrm{PAaH}$, of which the $M_{\mathrm{n}}$ and $M_{\mathrm{w}} / M_{\mathrm{n}}$ values were measured using gel-permeation chromatography (Figure 1). The $M_{\mathrm{n}}$ and $M_{\mathrm{w}} / M_{\mathrm{n}}$ values for free PAaH were $3.19 \times 10^{4}$ and 1.07 , respectively. The narrow $M_{\mathrm{w}} / M_{\mathrm{n}}$ value indicated that the polymerization proceeded in accordance with a controlled/living radical polymerization mechanism. The number-average degree of polymerization was calculated from $M_{\mathrm{n}}$ to be 153 . A polymer chain length similar to that of the free polymer can be grafted onto the surfaces of silica particles. ${ }^{23}$

Figure 2 shows attenuated total reflection-Fourier transfer infrared spectra of bare $\mathrm{SiO}_{2}, \mathrm{PAaH}-\mathrm{SiO}_{2}$ and $\mathrm{PAaH}$. In the spectrum of PAaH$\mathrm{SiO}_{2}$ (Figure 2b), new absorption peaks at 1547 (amido, $\mathrm{C}=\mathrm{O}$ ), 1649 (amido, $\mathrm{C}=\mathrm{O}$ ), 1721 (carboxyl group, $\mathrm{C}=\mathrm{O}$ ) and $2937 \mathrm{~cm}^{-1}(\mathrm{C}-\mathrm{H})$, which are characteristic of PAaH chains (Figure 2c), were evident. These results indicate that the grafting of PAaH onto the silica surface was successfully achieved by RAFT-controlled radical polymerization of $\mathrm{AaH}$ using $\mathrm{CPD}-\mathrm{SiO}_{2}$. Attenuated total reflection-Fourier transfer

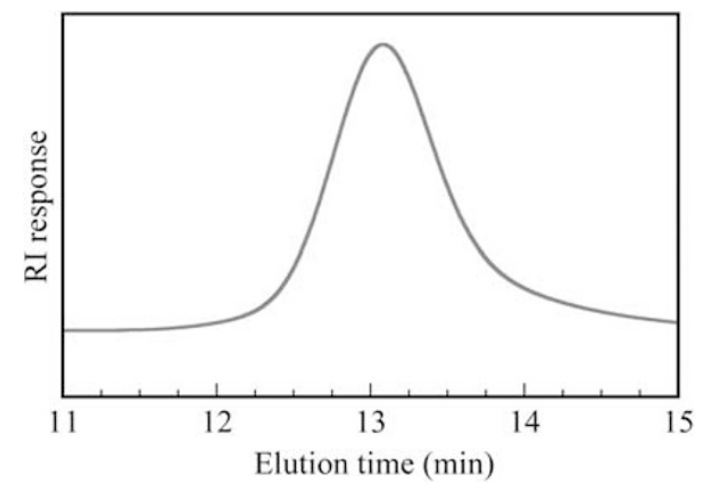

Figure 1 Gel-permeation chromatography elution curve for free poly(6(acrylamido)hexanoic acid) $(\mathrm{PaaH})\left(M_{\mathrm{n}}=3.19 \times 10^{4}\right.$ and $\left.M_{\mathrm{w}} / M_{\mathrm{n}}=1.07\right)$ in the supernatant after the preparation of $\mathrm{PAaH}_{-} \mathrm{SiO}_{2}$. A full color version of this figure is available at Polymer Journal online.

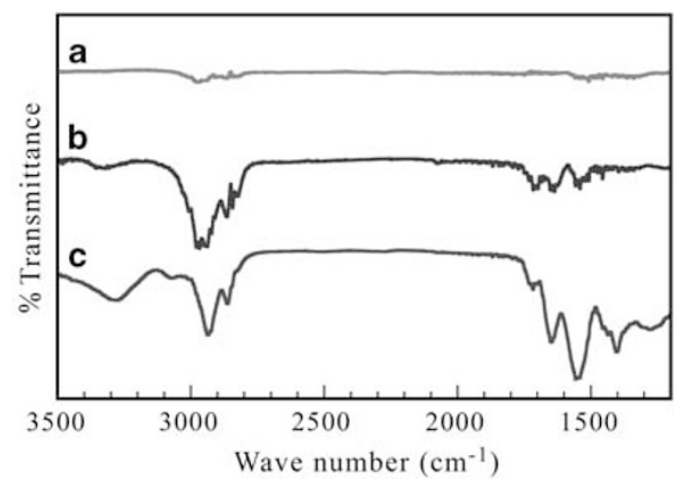

Figure 2 Attenuated total reflection-Fourier transfer infrared spectra of (a) bare $\mathrm{SiO}_{2}$, (b) $\mathrm{PAaH}-\mathrm{SiO}_{2}$ and (c) $\mathrm{PAaH}$ in the $3500-1200 \mathrm{~cm}^{-1}$ region. A full color version of this figure is available at Polymer Journal online. 
infrared spectra of $\mathrm{APSi}-\mathrm{SiO}_{2}$ and $\mathrm{CPD}-\mathrm{SiO}_{2}$ were also measured; however, the spectra were almost the same as that of bare $\mathrm{SiO}_{2}$. The amounts of immobilized APSi and CPD on the surface of the silica particles were too small, because the specific surface area of $11 \mu \mathrm{m}$ diameter $\mathrm{SiO}_{2}$ particles is much less than that of nanometer-sized particles.

Immobilization of the $\mathrm{PAaH}$ polymer chains onto the silica particles was confirmed by TGA. Figure 3 compares TGA curves for the bare$\mathrm{SiO}_{2}$ and $\mathrm{PAaH}-\mathrm{SiO}_{2}$ particles. The weight loss for bare $\mathrm{SiO}_{2}$ and $\mathrm{PAaH}-\mathrm{SiO}_{2}$ was 0 and $0.78 \%$, respectively. Exact weight loss values for APSi-SiO ${ }_{2}$ and $\mathrm{CPD}-\mathrm{SiO}_{2}$ could not be estimated from TGA, because the amounts of APSi and CPD immobilized onto the $\mathrm{SiO}_{2}$ particle surfaces were too small. Assuming the mass density of $\mathrm{PAaH}$ is $1.0 \mathrm{~g} \mathrm{~cm}^{-3}$, the graft density $(\Gamma)$ of $\mathrm{PAaH}$ on the surface of $\mathrm{SiO}_{2}$ was calculated from Equation (1) and TGA data to be 0.28 chains per $\mathrm{nm}^{2}$. The distance between graft sites $(D)$ and the thickness of the grafted PAaH layer $(H)$ were calculated from Equations (2) and (3) to be 1.89 and $14.8 \mathrm{~nm}$, respectively. The $H$ value for the PAaH layer of

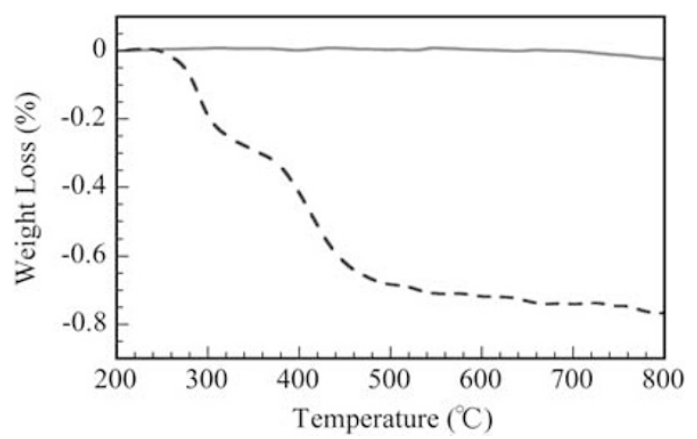

Figure 3 Thermogravimetric analysis curves for bare $\mathrm{SiO}_{2}(-)$ and $\mathrm{PAaH}-$ $\mathrm{SiO}_{2}(---)$ measured at a heating rate of $2{ }^{\circ} \mathrm{C}$ per min under nitrogen. A full color version of this figure is available at Polymer Journal online.
$14.8 \mathrm{~nm}$, which is smaller than that expected from computer simulation of the end-to-end distance of a fully extended PAaH chain length with a degree of polymerization of 153 can be calculated to be $38.2 \mathrm{~nm}$.

Figure 4 compares SEM images of untreated bare $\mathrm{SiO}_{2}$ and PAaH$\mathrm{SiO}_{2}$. The surface of bare $\mathrm{SiO}_{2}$ is smooth and without roughness (Figures $4 \mathrm{a}$ and $\mathrm{b}$ ). In contrast, the SEM images of $\mathrm{PAaH}-\mathrm{SiO}_{2}$ show a rough surface, which suggests that the $\mathrm{PAaH}$ polymer chain was grafted on the surface (Figures $4 \mathrm{c}$ and d). The shape of $\mathrm{PAaH}-\mathrm{SiO}_{2}$ was maintained as a fairly spherical shape after polymerization with vigorous stirring.

The $\mathrm{pH}$-responsive association and dissociation behavior of $\mathrm{PAaH}-$ $\mathrm{SiO}_{2}$ particles in water was investigated. Figure $5 \mathrm{a}$ shows photographs of the dispersibility of $\mathrm{PAaH}-\mathrm{SiO}_{2}$ in water at $\mathrm{pH} 3$ and 10 , immediately after vigorous shaking. The aqueous solution at $\mathrm{pH} 3$ was more transparent than that at $\mathrm{pH} 10$, because the $\mathrm{PAaH}-\mathrm{SiO}_{2}$ particles were precipitated and immediately settled at $\mathrm{pH} 3$. In contrast, the aqueous solution at $\mathrm{pH} 10$ was turbid, because the $\mathrm{PAaH}-\mathrm{SiO}_{2}$ particles were dispersed. Almost all bare silica particles precipitate and settle in water, because the density of the particles is $1.93 \mathrm{~g} \mathrm{~cm}^{-3}$. Figure $5 \mathrm{~b}$ shows time-course changes in the stability of aqueous $\mathrm{PAaH}-\mathrm{SiO}_{2}$ suspensions at $\mathrm{pH} 3$ and 10 . If the $11 \mu \mathrm{m}$ diameter particles are well dispersed, then the $\% T$ value at $600 \mathrm{~nm}$ is small. When the particles are completely precipitated and settled, $\% T$ at $600 \mathrm{~nm}$ becomes $100 \%$. The photograph shown in Figure $5 \mathrm{a}$ immediately after vigorous shaking corresponds to time $=0$ in Figure $5 \mathrm{~b} . \% \mathrm{~T}$ at $\mathrm{pH} 3$ and 10 at time $=0$ was 46.3 and $17.9 \%$, respectively. $\% T$ at $\mathrm{pH} 3$ and 10 increased with increasing time and reached a maximum of 97.9 and $89.2 \%$, respectively, at time $=180 \mathrm{~s}$. It is apparent that the $\mathrm{PAaH}-\mathrm{SiO}_{2}$ particles are stably dispersed in water at $\mathrm{pH} 10$ compared with those at $\mathrm{pH} 3$. At $\mathrm{pH} 3$, the $\mathrm{PAaH}$ graft chains cannot dissolve in water, because the pendant hexanoic acid groups are protonated. Therefore, the $\mathrm{PAaH}-$ $\mathrm{SiO}_{2}$ particles at $\mathrm{pH} 3$ tend to associate because of the hydrophobic interaction between the PAaH graft chains on the particle surfaces. At $\mathrm{pH} 10$, the PAaH graft chains can dissolve in water, because the
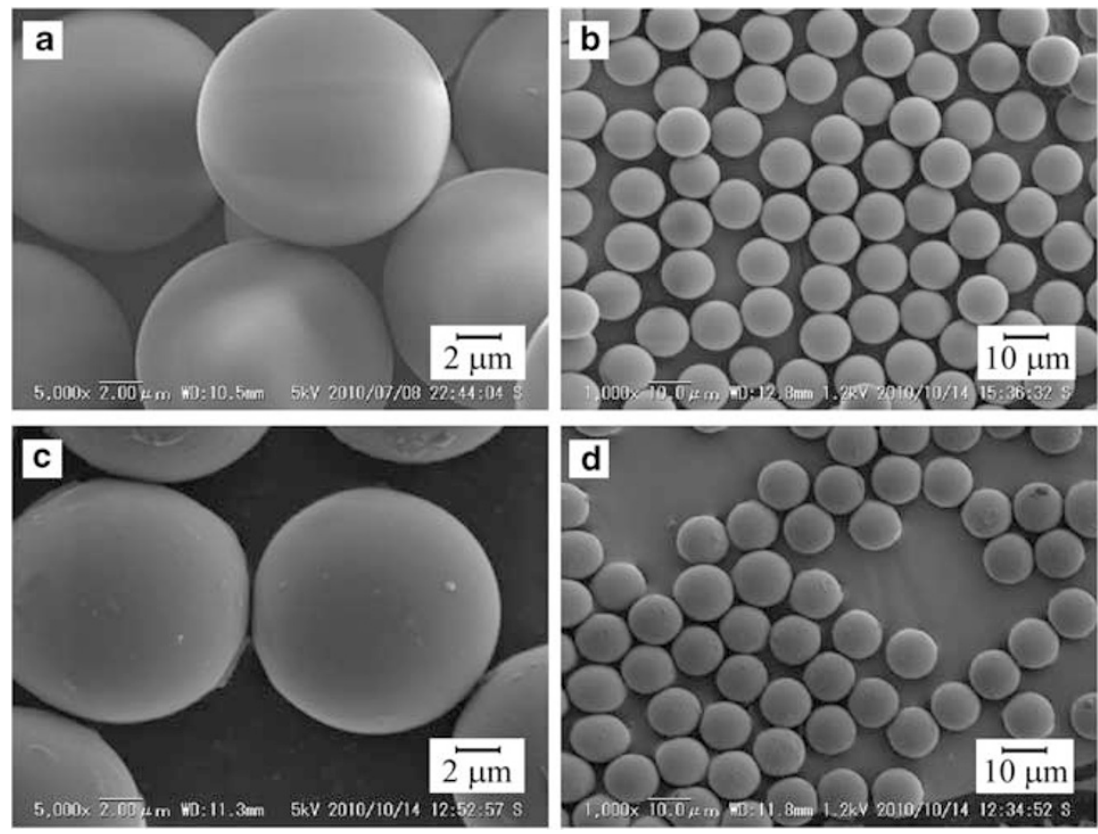

Figure 4 Scanning electron microscope images of $(\mathbf{a}, \mathbf{b})$ bare $\mathrm{SiO}_{2}$ and (c, d) $\mathrm{PAaH}-\mathrm{SiO}_{2}$. 
a

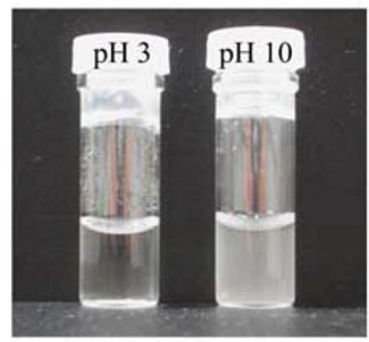

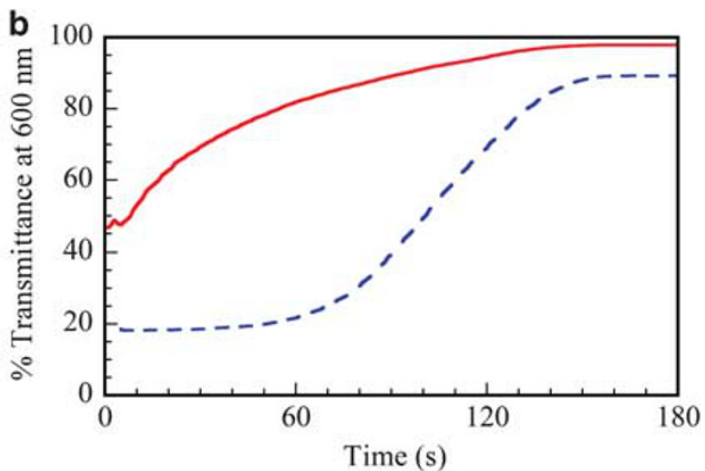

Figure 5 (a) Photograph of aqueous solutions of $\mathrm{PAaH}_{-} \mathrm{SiO}_{2}$ at $\mathrm{pH} 3$ and 10 immediately after vigorous shaking. (b) Time-course changes of percent transmittance $(\% T)$ at $600 \mathrm{~nm}$ for aqueous solutions of $\mathrm{PAaH}_{-} \mathrm{SiO}_{2}$ at $\mathrm{pH} 3(-)$ and $10(---)$.
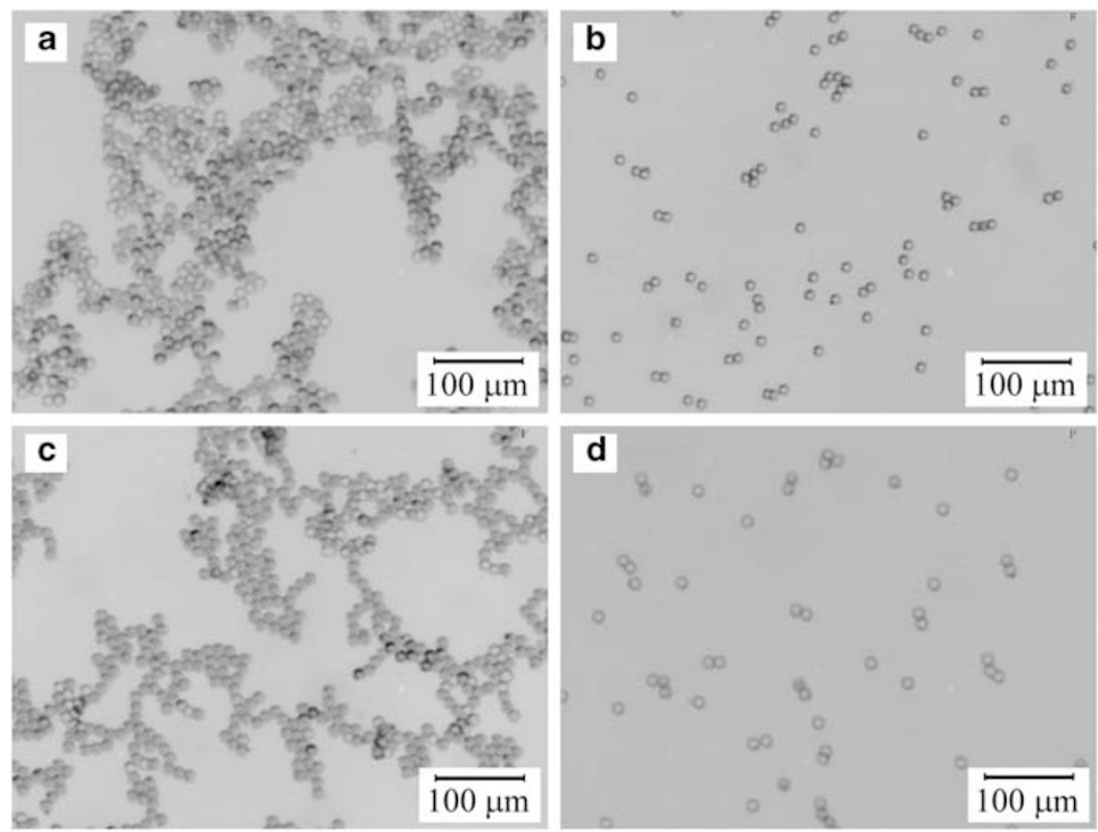

Figure 6 Optical microscope images of the reversible association and dissociation behavior of $\mathrm{PAaH}_{-} \mathrm{SiO}_{2}$ particles in water (a) at $\mathrm{pH} 3$, (b) at $\mathrm{pH} 10$ after addition of $\mathrm{NaOH}$ aqueous solution to $\mathbf{a}$, (c) at $\mathrm{pH} 3$ after addition of $\mathrm{HCl}$ aqueous solution to $\mathbf{b}$ and (d) at $\mathrm{pH} 10$ after addition of $\mathrm{NaOH}$ aqueous solution to c. A full color version of this figure is available at Polymer Journal online.

pendant hexanoate groups are ionized because of deprotonation. The $\mathrm{PAaH}-\mathrm{SiO}_{2}$ particles at $\mathrm{pH} 10$ tend to disperse because of an increase in surface wettability of the particles and the electrostatic repulsion of the pendant deprotonated carboxylate ions in the PAaH graft chains.

The $\mathrm{pH}$-induced flocculation and dispersion behavior of $\mathrm{PAaH}$ $\mathrm{SiO}_{2}$ suspensions in water was studied using optical microscopy. At $\mathrm{pH} 3$, flocculation of the particles was observed because of the hydrophobic interaction between protonated $\mathrm{PAaH}$ chains (Figure 6a). The pendant hexanoic acid groups in $\mathrm{PAaH}$ are hydrophobic, and the wettability of the $\mathrm{PAaH}-\mathrm{SiO}_{2}$ particle surface is decreased at $\mathrm{pH}$ 3. $\mathrm{NaOH}$ aqueous solution was added to the aqueous suspension of $\mathrm{PAaH}-\mathrm{SiO}_{2}$ to change the $\mathrm{pH}$ from 3 to 10 , and the suspension was mixed with a vortex mixer for 1 min (Figure 6b). The particles were dispersed separately because of the electrostatic repulsion between the pendant negatively charged hexanoate groups in the PAaH graft chains. At $\mathrm{pH} 10$, the $\mathrm{PAaH}$ graft chains become hydrophilic polyanions, because the pendant hexanoate groups are deprotonated. $\mathrm{HCl}$ aqueous solution was added to the aqueous suspension to change the $\mathrm{pH}$ from 10 to 3 and the suspension was mixed with a vortex mixer for $1 \mathrm{~min}$ (Figure $6 \mathrm{c}$ ). Flocculation of the particles was again observed at $\mathrm{pH} 3$. Furthermore, $\mathrm{NaOH}$ aqueous solution was added to the aqueous suspension to change the $\mathrm{pH}$ from 3 to 10 and the suspension was mixed with a vortex mixer for $1 \mathrm{~min}$ (Figure 6d), which again resulted in a dispersion of particles. These observations indicate that the surface wettability of $\mathrm{PAaH}-\mathrm{SiO}_{2}$ can be reversibly controlled by changing the $\mathrm{pH}$ of the solution.

Individual 'liquid marbles' were prepared by rolling a $7 \mu$ droplet of pure water over the dried $\mathrm{PAaH}-\mathrm{SiO}_{2}$ particles. The particles immediately coated and armored the water droplet and rendered it hydrophobic. These 'liquid marbles' clearly have significant surface roughness, which suggests that they are coated with particle multilayers rather than just a monolayer (Figure 7c). We performed SEM 

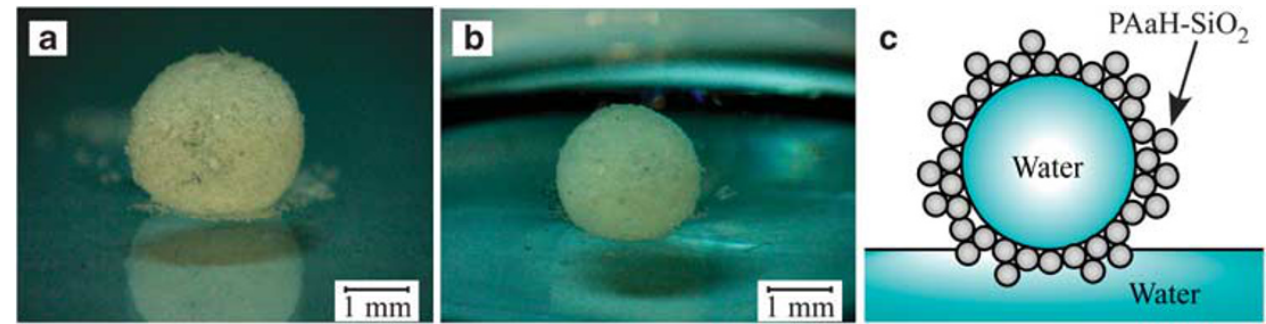

Figure 7 Optical microscope images of a 'liquid marble' of pure water covered with $\mathrm{PAaH}_{-} \mathrm{SiO}_{2}$ particles (a) on glass and (b) on a pure water pool. (c) Schematic illustration of a 'liquid marble' on the surface of a water pool, prepared using $\mathrm{PAaH}^{-} \mathrm{SiO}_{2}$ particles.

measurements for the 'liquid marbles' that were prepared using the $\mathrm{PAaH}-\mathrm{SiO}_{2}$ particles and an aqueous solution of gelatin to fix the structure. The SEM observation of the surface fine structure (Supplementary Figure S1) indicates that the $\mathrm{PAaH}-\mathrm{SiO}_{2}$ particles are accumulated at the surface of the 'liquid marbles.' The 'liquid marbles' can be transferred intact onto a hydrophilic substrate such as glass and even the planar surface of a water pool within a Petri dish, where they become highly mobile. Figures $7 \mathrm{a}$ and $\mathrm{b}$ shows 'liquid marbles' with a radius of $1 \mathrm{~mm}$, which are made of pure water, placed on a glass plate and pure water pool surface, respectively. In control experiments, no liquid marbles could be formed using bare $\mathrm{SiO}_{2}$ particles, because their surfaces can be well wetted by water. This control experiment indicated that the PAaH graft chains on the silica surface have a crucial role in the formation of 'liquid marbles.'

'Liquid marbles' were prepared by rolling a $7 \mu \mathrm{l}$ droplet of aqueous safranin dye solution over the dried $\mathrm{PAaH}-\mathrm{SiO}_{2}$ particles, which was then transferred to the water pool within a Petri dish. The $\mathrm{PAaH}-\mathrm{SiO}_{2}$ particles adsorbed at the air-water surface of the 'liquid marble' prevents the diffusion of water between the 'marble' interior and the bulk liquid. The water pool was not colored when the 'liquid marble' was stable on the planar air-water surface (Figure 8a), but the 'liquid marble' eventually burst on the water surface. The destabilization time, defined as the time required for the 'liquid marble' to burst after transfer to the water face, was measured. Measurements were recorded more than five times and the average destabilization time below pH 4 was $7.5 \mathrm{~min}$. Enhanced stabilities were achieved below $\mathrm{pH} 4$, which indicates that the protonated $\mathrm{PAaH}-\mathrm{SiO}_{2}$ particles are sufficiently hydrophobic to adsorb strongly at the air-water interface under these conditions. On the other hand, the liquid marbles were always unstable and burst above $\mathrm{pH} 9$ within $\sim 0.5 \mathrm{~min}$ of transfer to the water pool surface. This is because the non-protonated $\mathrm{PAaH}$ chains led to spontaneous desorption of the particles, followed by disintegration of the 'liquid marbles.' The resulting anionic $\mathrm{PAaH}-\mathrm{SiO}_{2}$ particles are then dispersed into the acidic bulk solution. The minimum $\mathrm{pH}$ required for long-term 'liquid marble' stability is closely correlated with the pKa value of 1-aminohexanoic acid (=4.37).

The 'liquid marble' consisting of aqueous safranin dye solution coated with $\mathrm{PAaH}-\mathrm{SiO}_{2}$ particles remained stable for several minutes when placed on the water pool at neutral or acidic $\mathrm{pH}$; however, it immediately burst and released safranin dye upon addition of a small amount of aqueous $\mathrm{NaOH}$ solution to the water pool (Figure 8b). A video of the $\mathrm{pH}$-responsive behavior of the 'liquid marble' is provided Supplementary Video S1 in the Supplementary Information. Therefore, a 'liquid marble' of water coated with $\mathrm{PAaH}-\mathrm{SiO}_{2}$ particles subsequently placed on the water pool rapidly disintegrated in response to the alkalinity of the water pool. When pure water instead of the aqueous $\mathrm{NaOH}$ solution was added to the water pool, the 'liquid marble' remained unchanged.
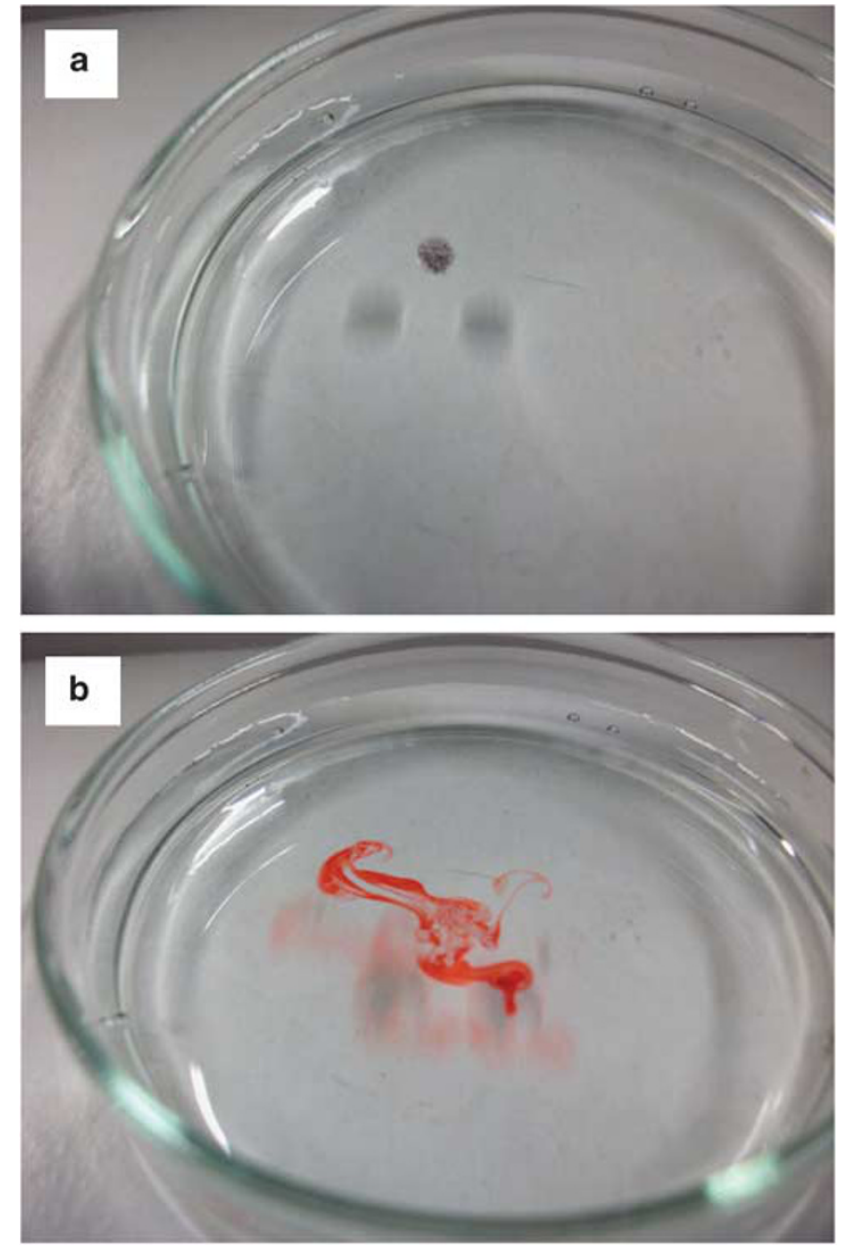

Figure 8 Photographs of a floatable 'liquid marble' consisting of an aqueous safranin dye solution covered with $\mathrm{PAaH}-\mathrm{SiO}_{2}$ particles on a pure water pool in a Petri dish (a) before and (b) after the addition of $\mathrm{NaOH}$ aqueous solution to the water pool.

\section{CONCLUSIONS}

$\mathrm{pH}$-responsive $\mathrm{PAaH}$ chains were grafted from the surface of CPD$\mathrm{SiO}_{2}$ via RAFT-controlled radical polymerization. The graft density of $\mathrm{PAaH}$ and the thickness of the grafted PAaH layer on the surface of $\mathrm{SiO}_{2}$ were 0.28 chains per $\mathrm{nm}^{2}$ and $14.8 \mathrm{~nm}$, respectively. The PAaH$\mathrm{SiO}_{2}$ particles in water at $\mathrm{pH} 3$ tend to associate because of the hydrophobic interaction between $\mathrm{PAaH}$ graft chains on the $\mathrm{PAaH}-$ $\mathrm{SiO}_{2}$ surface. In contrast, the $\mathrm{PAaH}-\mathrm{SiO}_{2}$ particles tend to disperse in water at $\mathrm{pH} 10$ because of an increase in surface wettability and the 
electrostatic repulsion of the $\mathrm{PAaH}$ graft chains. Finally, 'liquid marbles' were prepared using $\mathrm{PAaH}-\mathrm{SiO}_{2}$ particles and the stability of the 'liquid marbles' was confirmed to change according to $\mathrm{pH}$.

\section{CONFLICT OF INTEREST}

The authors declare no conflict of interest.

\section{ACKNOWLEDGEMENTS}

We are grateful to Dr H Kawasaki (Kansai University) for ATR-FTIR investigations. This work was supported by a Grant-in-Aid (No. 21106518) for Scientific Research on Innovative Areas, 'Molecular Soft-Interface Science,' from the Ministry of Education, Culture, Sports, Science and Technology of Japan.

1 Ramsden, W. Separation of solids in the surface-layers of solutions and 'suspensions' (observations on surface-membranes, bubbles, emulsions, and mechanical coagulation). Proc. R. Soc. London 72, 156-164 (1903).

2 Pickering, S. U. CXCVI.-emulsions. J. Chem. Soc. Trans. 91, 2001-2021 (1907)

3 Amalvy, J. I., Armes, S. P., Binks, B. P., Rodrigues, J. A. \& Unali, G.- F. Use of stericallystabilised polystyrene latex particles as a pH-responsive particulate emulsifier to prepare surfactant-free oil-in-water emulsions. Chem. Commun. 1826-1827 (2003).

4 Binks, B. P. \& Lumsdon, S. O. Pickering emulsions stabilized by monodisperse latex particles: effects of particle size. Langmuir 17, 4540-4547 (2001).

5 Li, J. \& Stöver, H. D. H. Doubly pH-responsive pickering emulsion. Langmuir 24, 13237-13240 (2008).

6 Aussilious, P. \& Quere, D. Properties of liquid marbles. Proc. R. Soc. London Ser. A 426, 973-999 (2006).

7 Fujii, S. \& Murakami, R. Microparticles as foam and liquid marble stabilizers. KONA 26, 153-166 (2008).

8 Binks, B. P. \& Murakami, R. Phase inversion of particle-stabilized materials from foams to dry water. Nat. Mater. 5, 865-869 (2006).

9 Mahadevan, L. \& Pomeau, Y. Rolling droplets. Phys. Fluids 11, $2449-2454$ (1999).

10 Aussillous, P. \& Quéré, D. Liquid marbles. Nature 411, 924-927 (2001).

11 Rao, A. V., Kulkarni, M. M. \& Bhagat, S. D. Transport of liquids using superhydrophobic aerogels. J. Colloid Interface Sci. 285, 413-418 (2005).

12 Wang, W., Bray, C. L., Adams, D. J. \& Cooper, A. I. Methane storage in dry water gas hydrates. J. Am. Chem. Soc. 130, 11608-11609 (2008).

13 Bhosale, P. S., Panchagnula, M. V. \& Stretz, H. A. Mechanically robust nanoparticle stabilized transparent liquid marbles. Appl. Phys. Lett. 93, 034109-1-3 (2008).
14 Dandan, M. \& Erbil, H. Y. Evaporation rate of graphite liquid marbles: comparison with water droplets. Langmuir 25, 8362-8367 (2009).

15 Bormashenko, E., Pogreb, R., Bormashenko, Y., Musin, A. \& Stein, T. New investigations on ferrofluidics: ferrofluidic marbles and magnetic-field-driven drops on superhydrophobic surfaces. Langmuir 24, 12119-12122 (2008).

16 Bormashenko, E., Pogreb, R., Whyman, G., Musin, A., Bormashenko, Y. \& Barkay, Z. Shape, vibrations, and effective surface tension of water marbles. Langmuir 25 , 1893-1896 (2009).

17 Gao, L. \& McCarthy, T. J. Ionic liquid marbles. Langmuir 23, 10445-10447 (2007).

18 Matsukuma, D., Watanabe, H., Yamaguchi, H. \& Takahara, A. Preparation of lowsurface-energy poly[2-(perfluorooctyl)ethyl acrylate] microparticles and its application to liquid marble formation. Langmuir 27, 1269-1274 (2011).

19 McHale, G., Herbertson, D. L., Elliott, S. J., Shirtcliffe, N. J. \& Newton, M. I. Electrowetting of nonwetting liquids and liquid marbles. Langmuir 23, 918-924 (2007).

20 Dupin, D., Armes, S. P. \& Fujii, S. Stimulus-responsive liquid marbles. J. Am. Chem. Soc. 131, 5386-5387 (2009).

21 Fujii, S., Kameyama, S., Armes, S. P., Dupin, D., Suzaki, M. \& Nakamura, Y. pHresponsive liquid marbles stabilized with poly(2-vinylpyridine) particles. Soft Matter $\mathbf{6}$, 635-640 (2010).

22 Lattuada, M. \& Hatton, T. A. Preparation and controlled self-assembly of Janus magnetic nanoparticles. J. Am. Chem. Soc. 129, 12878-12889 (2007).

23 Zhao, Y. \& Perrier, S. Reversible addition-fragmentation chain transfer graft polymerization mediated by fumed silica supported chain transfer agents. Macromolecules 40 , 9116-9124 (2007).

24 Mitsukami, Y., Donovan, M. S., Lowe, A. B. \& McCormick, C. L. Water-soluble polymers. 81. Direct synthesis of hydrophilic styrenic-based homopolymers and block copolymers in aqueous solution via RAFT. Macromolecules 34, 2248-2256 (2001).

25 Shibaev, V. P., Platé, N. A. \& Freidzon, Y. S. Thermotropic liquid crystalline polymers. I. Cholesterol-containing polymers and copolymers. J. Polym. Sci. Chem. Ed. 17, 1655-1670 (1979).

26 Li, C., Han, J., Ryu, C. Y. \& Benicewicz, B. C. A versatile method to prepare RAFT agent anchored substrates and the preparation of PMMA grafted nanoparticles. Macromolecules 39, 3175-3183 (2006).

$27 \mathrm{Li}$, C. \& Benicewicz, B. C. RAFT polymerization of methyl methacrylate from silica nanoparticles. Polym. Prep. 46, 459-460 (2005).

28 Newton, M. I., Herbertson, D. L., Elliott, S. J., Shirtcliffe, N. J. \& McHale, G. Electrowetting of liquid marbles. J. Phys. D. Appl. Phys. 40, 20-24 (2007).

29 Berger, S., Synytska, A., Ionov, L., Eichhorn, K. J. \& Stamm, M. Stimuli-responsive bicomponent polymer Janus particles by 'grafting from'/'grafting to' approaches. Macromolecules 41, 9669-9676 (2008).

30 Ionov, L., Zdyrko, B., Sidorenko, A., Minko, S., Klep, V., Luzinov, I. \& Stamm, M. Gradient polymer layers by 'grafting to' approach. Macromol. Rapid Commun. 25, 360-365 (2004).

31 Zhao, Y. \& Perrier, S. Synthesis of well-defined homopolymer and diblock copolymer grafted onto silica particles by z-supported RAFT polymerization. Macromolecules $\mathbf{3 9}$, 8603-8608 (2006).

Supplementary Information accompanies the paper on Polymer Journal website (http://www.nature.com/pj) 